Pacific Journal of Mathematics

TWO PROBE EMS OF KLREPA 


\title{
ON TWO PROBLEMS OF KUREPA
}

\author{
J. C. SHEPHER DSON
}

We prove ${ }^{\mathbf{1}}$ :

THEOREM 1. There exists a denumerable ramified partially ordered set with the property that there is no chain meeting all maximal anti-chains and no antichain meeting all maximal chains.

(Here a chain (anti-chain) is a set of elements every pair of which are comparable (incomparable). A ramified partially ordered set $S$ is one in which for each $x$ in $S$ the set of elements $\leq x$ forms a chain.)

Proof. We denote by $F$ the set of all finite sequences $\left(\alpha_{1}, \alpha_{2}, \ldots, \alpha_{k}\right)$ of integers. We use Greek letters $\alpha, \beta$ to denote elements of $F$, we denote by $l\left(\alpha_{i}\right)$ the length of $\alpha$ (that is, the number of terms in the sequence $\alpha$ ) and by $\alpha_{i}$ (for $i=1, \cdots, l(\alpha)$ ) the $i$ th term in the sequence $\alpha ; i, k$ are used throughout as variables for positive integers. If $n$ is an integer we denote by $(\alpha, n)$ the sequence $\left(\alpha_{1}, \ldots, \alpha_{l}(\alpha), n\right)$ obtained by adding the term $n$ to the sequence $\alpha$. We define $\alpha \leq \beta$ to hold when conditions

$$
\begin{aligned}
& A: l(\alpha) \leq l(\beta), \\
& B: a_{i}=\beta_{i} \text { for } i=1, \cdots, l(\alpha)-1,
\end{aligned}
$$

and

$$
C: \alpha_{l(\alpha)} \leq \beta_{l(\alpha)}
$$

are all satisfied. It is easily seen that this relation ' $\leq$ ' is a ramified partial ordering of $F$.

Now let $L_{\alpha}$ denote the chain of elements $\leq \alpha_{\text {, let }} C_{\alpha}$ denote the set of

${ }^{1}$ This answers two questions posed by Kurepa (Pacific J. Math. 2 (1952), 323-326). Answers to these questions were found independently by W. Gustin; see the reviews in Math. Rev. 14 (March, 1953), p. 255 by W. Gustin, and in Zentralblatt für Math., 64 (1953), p. 52, by J. C. Shepherdson.

Received March 25, 1953, and in revised form on May 25, 1953.

Pacific J. Math., 4. (1954), 301-304 
elements of the form $(\alpha, u)$, where $u$ runs through all integer values, and let $L\left(C_{\alpha}\right)$ denote the set of elements less than all elements of $C_{\alpha}$. Then we can easily prove

(i) $C_{a}$ is a chain,

(ii) the elements of $F$ which are comparable with all elements of $C_{\alpha}$ belong to $C_{a} \cup L\left(C_{a}\right)$,

(iii) $L\left(C_{\alpha}\right)=L_{\alpha}$,

and hence

(iv) $C_{a} \cup L_{a}$ is a maximal chain.

We now prove by reductio ad absurdum that no anti-chain meets all maximal chains. Suppose the anti-chain $A$ meets all maximal chains. Clearly it has just one point in common with each maximal chain. It is easily seen that the set $T_{0}$ of all elements $(u)$ of length one is a maximal chain. Hence there exists a unique integer $a_{1}$ such that $\left(a_{1}\right) \in A$. Take $n_{1}=a_{1}-1$. Then the chain $C_{1}$ of elements $\leq\left(n_{1}\right)$ consists of all the elements $(u)$ with $u<a_{1}$, and is therefore a subchain of $T_{0}$ not meeting $A$. We now define for each positive integer $k$ by induction on $k$ an integer $n_{k}$ such that the chain $C_{k}$ of elements $\leq\left(n_{1}, \cdots, n_{k}\right)$ does not meet $A$. We have just disposed of the case $k=1$. Suppose then that $k>1$ and that $n_{1}, \ldots, n_{k-1}$ are already defined so that the chain $C_{k-1}$ of elements $\leq\left(n_{1}, \ldots, n_{k-1}\right)$ does not meet $A$. By (iv) the set $T_{k-1}{ }^{2}$ of all elements of the form $\left(n_{1}, \ldots, n_{k-1}, u\right)$ together with $C_{k-1}$ forms a maximal chain. By hypothesis this meets $A$ and $C_{k-1}$ does not; hence there exists a unique integer $a_{k}$ such that $\left(n_{1}, \ldots, n_{k-1}, a_{k}\right) \in A$. Take $n_{k}=a_{k}-1$. Clearly $C_{k}$ does not meet $A$. This completes the definition by induction of a sequence $n_{1}, n_{2}, \ldots$ of integers such that for all positive integers $k$ the chain $C_{k}$ of elements $\leq\left(n_{1}, \cdots, n_{k}\right)$ does not meet $A$. Now

$$
\left(n_{1}, \cdots, n_{k}\right)<\left(n_{1}, \cdots, n_{k}, n_{k+1}\right)
$$

so $C_{k} \subseteq C_{k+1}$. Hence the set

$$
C=\sum_{k=1}^{\infty} C_{k}
$$

${ }^{2}$ With the previous notation $T_{k-1}=C_{\left(n_{1}, \cdots, n_{k-1}\right)}, C_{k-1}=L\left(n_{1}, \cdots, n_{k-1}\right)$. 
is a chain. Now let $\alpha$ be an element of $F$ comparable with all elements of $C$. Then

$$
\alpha \ngtr\left(n_{1}, n_{2}, \cdots, n_{l(\alpha)+1}\right),
$$

so

$$
\alpha \leq\left(n_{1}, n_{2}, \cdots, n_{l(\alpha)+1}\right)
$$

that is, $\alpha \in C_{l(\alpha)+1}$, so $\alpha \in C$. Hence $C$ is a maximal chain. But $C$ cannot meet $A$ since none of $C_{1}, C_{2}, \ldots$ meet $A$. Thus we have obtained a contradiction from the assumption that there exists an anti-chain meeting all maximal chains.

We now prove by reductio ad absurdum that no chain meets all maximal antichains. Suppose $C$ is a chain meeting all maximal anti-chains. We note first that the lengths of the elements of $C$ are unbounded. To prove this it is clearly enough to show that for each positive integer $k$ there are maximal anti-chains all of whose elements are of length greater than $k$. It is easily seen that a set $A_{k}$ with this property may be defined as follows: Denote by $S_{k}$ the set of all elements of $F$ of length $k$, and by $N$ the set of elements $\left(\alpha_{1}, \ldots, \alpha_{n}\right)$ of $F$ all of whose terms $\alpha_{1}, \ldots, \alpha_{n}$ are $<0$. Let $A_{k}$ be the set of all elements of the form $(\alpha, 0)$ for $\alpha \in S_{k}$ together with all elements of the form $(\alpha, \beta, 0)$ for $\alpha \in S_{k}, \beta \in N$. (Here $(\alpha, \beta, 0)$ stands for $\left(\alpha_{1}, \cdots, \alpha_{l(\alpha)}, \beta_{1}, \cdots, \beta_{l}(\beta), 0\right)$.)

We note secondly that it follows easily from the definition of ' $\leq$ ' that since $C$ is a chain, all elements of $C$ of length $>i$ have the same $i$ th term.

In view of these two observations, it follows that we may define a unique sequence $n_{1}, n_{2}, n_{3}, \ldots$ of integers by putting $n_{i}$ equal to the common $i$ th term of the elements of $C$ of length greater than $i$. Now let $A$ be the set consisting of all sequences $\alpha$ such that $\alpha_{i} \leq n_{i}$ for $1 \leq i<l(\alpha)$ and $\alpha_{l(\alpha)}=n_{l(\alpha)}+1$. This set $A$ is easily seen to be a maximal anti-chain, so by hypothesis there exists an element $\alpha$ belonging to $C$ and $A$. Let $\beta$ be any element of $C$ of greater length than $\alpha$. Since $\alpha, \beta \in C$ they are comparable, so, since $l(\beta)>l(\alpha)$, we must have $\alpha<\beta$. From the definition of $n_{1}, n_{2}, \ldots$, we have $\alpha_{i}=n_{i}$ for $i<l(\alpha)$ and, since $\alpha<\beta$,

$$
\alpha_{l(a)} \leq \beta_{l(a)}=n_{l(\alpha)}
$$




$$
\alpha<\left(n_{1}, n_{2}, \cdots, n_{l(\alpha)-1}, n_{l(\alpha)}+1\right)
$$

but both these are elements of the anti-chain $A$ and so are incomparable. So our hypothesis that there exists a chain meeting all maximal anti-chains leads to a contradiction; this completes the proof of Theorem 1 .

By using the same sort of argument as Kurepa one can use the example of Theorem 1 to show, by means of the axiom of choice:

THEOREM 2. A sufficient condition for a nonvoid set $S$ to be finite is that in every ramified partial ordering of $S$ there exists a chain meeting all maximal anti-chains (or, '.. there exists an anti-chain meeting all maximal chains').

By Kurepa's result both these conditions are also necessary conditions for $S$ to be finite.

UNIVERSITY OF BRISTOL 


\section{PACIFIC JOURNAL OF MATHEMATICS}

\section{EDITORS}

\author{
M.M. SCHIFFE R* \\ Stanford University \\ Stanford, California \\ E. HEWITT \\ University of Washington \\ Seattle 5, Washington
}

\author{
R.P. DILWORTH \\ Calif ornia Institute of Technology \\ Pasadena 4, California \\ E. F. BECKENBACH** \\ University of California \\ Los Angeles 24, California
}

\section{ASSOCIATE EDITORS}

$\begin{array}{llll}\text { H. BUSEMANN } & \text { P.R. HALMOS } & \text { BØRGE JESSEN } & \text { J. J. STOKER } \\ \text { HERBERT FEDERER } & \text { HEINZ HOPF } & \text { PAUL LÉVY } & \text { E. G. STRAUS } \\ \text { MARSHALL HALL } & \text { R.D. JAMES } & \text { GEORGE PÓLYA } & \text { KÔSAKU YOSIDA }\end{array}$

\section{SPONSORS}

UNIVERSITY OF BRITISH COLUMBIA

UNIVERSITY OF SOUTHERN CALIFORNIA

CALIFORNIA INSTITUTE OF TECHNOLOGY

UNIVERSITY OF CALIFORNIA, BERKELEY

STANFORD RESEARCH INSTITUTE

UNIVERSITY OF CALIFORNIA, DAVIS

STANFORD UNIVERSITY

UNIVERSITY OF CALIFORNIA, LOS ANGELES

WASHINGTON STATE COLLEGE

UNIVERSITY OF CALIFORNIA, SANTA BARBARA

UNIVERSITY OF WASHINGTON

UNIVERSITY OF NEVADA

OREGON STATE COLLEGE

AMERICAN MATHEMATICAL SOCIETY

UNIVERSITY OF OREGON

HUGHES AIRCRAFT COMPANY

Mathematical papers intended for publication in the Pacific Journal of Mathematics should be typewritten (double spaced), and the author should keep a complete copy. Manuscripts may be sent to any of the editors. Manuscripts intended for the outgoing editors should be sent to their successors. All other communications to the editors should be addressed to the managing editor, E.G. Straus, at the University of California Los Angeles 24, California.

50 reprints of each article are furnished free of charge; additional copies may be obtained at cost in multiples of 50 .

The Pacific Journal of Mathematics is published quarterly, in March, June, September, and December. The price per volume (4 numbers) is $\$ 12.00$; single issues, $\$ 3.50$; back numbers (Volumes $1,2,3$ ) are available at $\$ 2.50$ per copy. Special price to individual faculty members of supporting institutions and to individual members of the American Mathematical Society: $\$ 4.00$ per volume; single issues, $\$ 1.25$.

Subscriptions, orders for back numbers, and changes of address should be sent to the publishers, University of California Press, Berkeley 4, California.

Printed at Ann Arbor, Michigan. Entered as second class matter at the Post Office, Berkeley, California.

* To be succeeded in 1955, by H.L. Royden, Stanford University, Stanford, California.

** To be succeeded in 1955, by E.G. Straus, University of California, Los Angeles 24, Calif.

UNIVERSITY OF CALIFORNIA PRESS - BERKELEY AND LOS ANGELES

COPYRIGHT 1954 BY PACIFIC JOURNAL OF MATHEMATICS 


\section{Pacific Journal of Mathematics}

\section{Vol. 4, No. $2 \quad$ June, 1954}

Henry Ludwig Alder, Generalizations of the Rogers-Ramanujan

identities ........................................ 161

E. M. Beelsey, Concerning total differentiability of functions of class $P$. . . 169

L. Carlitz, The number of solutions of some special equations in a finite

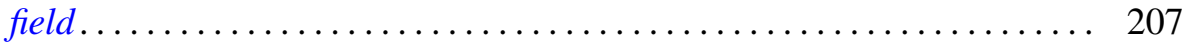

Marshall Hall, On a theorem of Jordan ............................ 219

J. D. Hill, Remarks on the Borel property..................... 227

Joseph Lehner, Note on the Schwarz triangle functions ............... 243

Arthur Eugene Livingston, A generalization of an inequality due to

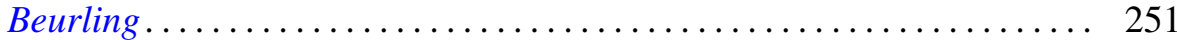

Edgar Reich, An inequality for subordinate analytic functions .......... 259

Dan Robert Scholz, Some minimum problems in the theory of functions ... . 275

J. C. Shepherdson, On two problems of Kurepa ................. 301

Abraham Wald, Congruent imbedding in F-metric spaces ............ 305

Gordon L. Walker, Fermat's theorem for algebras ............... 317 